\title{
Influences of teaching style and perceived care of instructor on retention of underrepresented groups in STEM
}

\author{
Melissa H. Dancy ${ }^{1}$, Katherine Rainey ${ }^{1}$, Roslyn Mickelson ${ }^{2}$, Elizabeth Stearns ${ }^{2}$, and Stephanie Moller ${ }^{2}$ \\ ${ }^{1}$ Department of Physics, University of Colorado, Boulder, CO 80309 \\ ${ }^{2}$ Department of Sociology, University of North Carolina - Charlotte, Charlotte, NC 28223
}

\begin{abstract}
We report on an analysis of interviews with 112 STEM majors and 49 students who started but dropped a STEM major. Interviewees are diverse across both race and gender. Students were asked about the level of interactivity in their college science courses and if they preferred a different emphasis. They were also asked if they thought their professors cared about them and their learning. Analysis indicates all demographics prefer more interactivity than they experienced and that women may be disproportionately discouraged by lecture-based teaching. Those who dropped a STEM major and minority women report the lowest levels of care from their professors. Additionally, as levels of classroom interactivity increased students reported increased levels of feeling that their professors cared about their learning.
\end{abstract}

Keywords: Gender, Race, Teaching Style, Affective

\section{INTRODUCTION}

As part of a larger study of underrepresented groups in STEM majors, we consider the impact of teaching style in relation to students' perception of care by instructors. Teaching styles in STEM are increasingly shifting from a lecture-based approach to a more interactive approach. While the evidence for increased learning and retention across all groups in interactive classrooms is robust, less is known about the potential impact of this shift on students of varying demographics.

Within physics, the most extensive effort at addressing the impact of interactive vs. lecture-based teaching on underrepresented groups was undertaken by Madsen et. al. [1] who reviewed 26 published studies on the gender gap on concept inventories in physics. They found mixed results regarding impact of teaching style, with interactive methods having positive, negative or neutral impacts on the gender gap depending on the study. Additionally, Beichner et. al. [2] report on extensive data from the SCALE-UP project indicating that failure rates in this interactive-intensive teaching environment are greatly reduced compared to lecture.

So, while the evidence indicates potentially positive impacts of interactive teaching on the success and retention of underrepresented groups, this data is at times unclear and more understanding is needed. We note this pattern is especially true for students of color (with a near complete dearth of research on women of color), as the majority of studies of underrepresented groups focus on women, typically white women.

\section{INTERVIEW DATA}

We conducted interviews with seniors who were either majoring in STEM (majors, $\mathrm{N}=112$ ) or who reported starting a STEM major but completed a major in another field (leavers, $\mathrm{N}=49$ ) across the wide array of North Carolina (NC) public universities, including large research universities, smaller regional schools, and several historically Black colleges. We oversampled for underrepresented students (in gender and race) in our interview selection process. Demographics of the interview sample are shown in Table 1 below.

TABLE 1. Demographics of majors and leavers interviewed.

\begin{tabular}{lcc} 
Sample & Women & Men \\
\hline White & 59 & 37 \\
Non-White & 60 & 45
\end{tabular}

Due to small numbers, and for simplicity, we report race in two categories: white (privileged status) and non-white (non-privileged status). All students interviewed had also attended high school in NC and can thus be considered domestic. A breakdown of the racial 
identification of the non-white sample is provided in Fig. 1. Racial status was self-identified by the participants. The majority of the non-whites in our sample were Black, as they are the dominant non-white racial group in the colleges our interviewees attended.

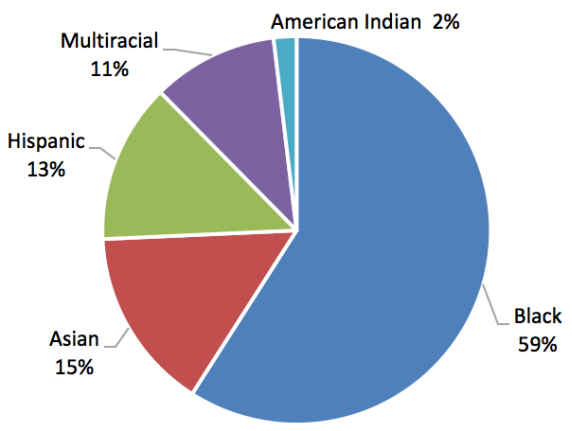

Non-white Racial Distribution

FIG 1. Distribution of Non-White participants in the sample. Black participants made up $59 \%$ of the nonwhite participants.

All interview questions focused on understanding student experiences with STEM and decisions that led to their choice of major. In this paper, we focus on three interview questions. Question 3 was asked earlier in the interview, while Questions 1 and 2 were asked together towards the end. We report analysis of the following questions about students' experiences in their college STEM courses related to teachers and teaching style:

1. To what extent did your \{major or dropped major\} instructors lecture vs. use more active approaches such as, encouraging student discussion, cooperative learning and hands on activities?

2. (following \#1) Would you have preferred a different emphasis?

3. Do you think your \{major or dropped major\} instructors cared about you and your learning?

Interviews were transcribed then coded using NVivo. For various reasons, not every person interviewed was coded for every question asked. For example, the answer given may have been too unclear to code. Therefore, numbers reported in each individual analysis may not add up to the total.

\section{TEACHING STYLE}

Student responses to the questions about teaching style were coded based on what style they reported receiving (lecture, mixed, or interactive). The mixed category was created to account for the numerous students who reported both styles in the same course or at different times. Then, based on their response to the question about their preference, they were also coded as interactive, mixed, or lecture learning in their preference. For example, if a student reported their instruction was mixed and that they would have preferred more interactivity then they were coded as interactive learning in their preference. This gave us a picture of their perceptions and preferences of classroom environment.

We found no effect for race in our analysis of reported and preferred teaching style. Thus, we present our findings based on gender and majors status, as can be seen in Fig. 2 and Fig. 3 below.

FIG 2. Reported teaching style of college instructors by major status and gender. Female leavers had the highest reporting of lecture-based learning and lowest reporting

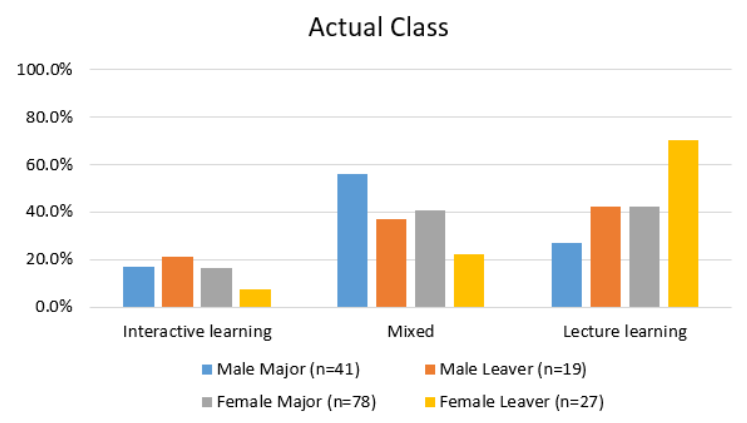

of interactive learning. Interactive learning was the least reported teaching style for all groups.

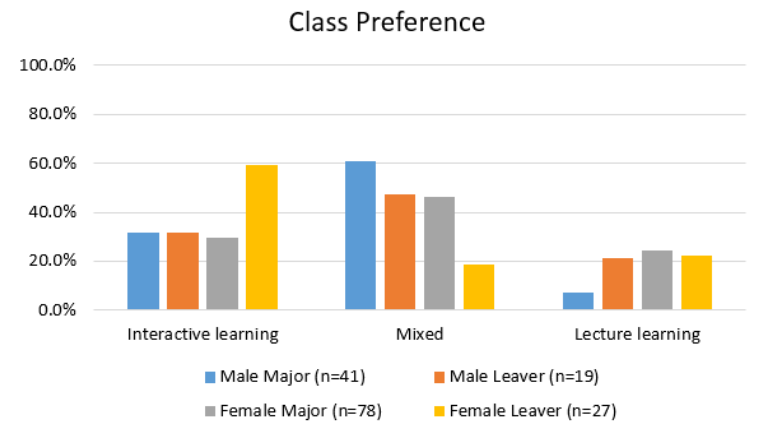

FIG 3. Reported teaching style preference by major status and gender. Female leavers had the highest reported preference for interactive learning.

\section{A. Students encounter lecture-based teaching but want more interactive teaching.}

Students reported lecture-based teaching 3x more often than interactive teaching. However, only $20 \%$ of students reported a preference for lecture-based teaching. The preference for more interactive teaching than what they encountered was found across all groups (race, gender, and major status). 


\section{B. Lecture-based teaching may discourage women from STEM majors.}

The pattern of female leavers stands out. Women who started but dropped a STEM major report the highest levels of lecture-based teaching and the greatest preference for interactivity. Our small numbers and inability to distinguish correlation from causation limit the conclusions that can be drawn. However, our data do indicate the possibility that lecture-based teaching may negatively impact retention for women and that further research should be done. The following is a typical response from a female leaver:

" $\{$ My chemistry professor $\}$ never stopped for questions ... my learning style and his teaching style just were not compatible at all ... he literally killed every love of science that I had .... I think it was primarily the chemistry class that caused me to drop the STEM major\}. This man was not very helpful or sensitive to anybody's problem ... \{he\} was just kind of closed off and didn't care about anybody."

Of note, female majors had similar teaching style preferences and experiences as both male majors and leavers. Thus, the women who expressed a greater preference for interactive teaching were also the ones likely to leave STEM.

\section{PERCEPTIONS OF CARE OF INSTRUCTORS}

Student responses to the question about perceived care of instructors in their STEM major were coded as yes (my professors cared) or no (my professors did not care) with the possibility of a student being coded as both if they spoke differently of different professors. Findings are presented in Fig. 4.

\section{A. Majors report higher levels of care than leavers.}

Across all demographic groups, majors report feeling their professors cared about them and their learning more than leavers. Among all majors, 75\% reported feeling their STEM professors cared about them and their learning. While it is not surprising that majors reported higher levels of care than leavers it is worth noting that all of these students were seniors nearing graduation in their field. A significant number $(25 \%)$ reported not feeling their professors cared about their learning, which illuminates an area of concern to be investigated further.

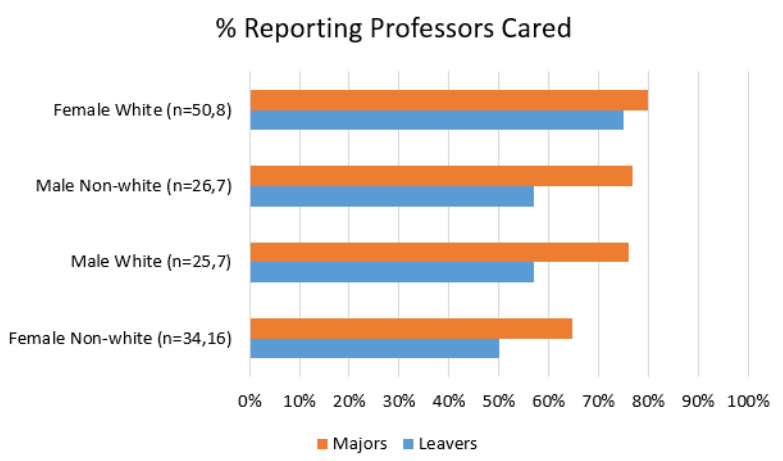

FIG 4. Percent of students reporting feeling their professors cared about them and their learning. $\mathrm{N}$ values are given as ( $\mathrm{n}=$ majors, leavers $)$.

\section{B. Women of color report the lowest levels of care.}

While the results for white and non-white men were nearly identical, white women reported the most care while women of color reported the least. Only $60 \%$ of the women of color in our sample reported feeling their professors cared about them.

Reasons given by women of color for not feeling their professor cared varied. A common reason was poor or distant teaching. For example, an Asian female major stated: "I don't think they cared about me. I think they wanted me to do well but they just don't know how to approach it in a way that everyone can get something out of it and learn at a pace that is reasonable. They have a certain set of goals and objectives to get through". Large class sizes were also a common reason attributed to feeling lack of care. A multiracial female major noted: "I didn't feel they cared\} because there are so many kids in the class I think it's hard to really connect with your teachers." Unfriendly interactions with individual teachers were also frequently mentioned. For example, one women told a story of feeling unsupported by her professor after returning to school after a family death.

\section{INTERSECTION OF TEACHING STYLE AND PERCEIVED CARE}

We then combined the data to see how respondents' perceptions of the care of their instructors intersected with their reports of teaching style. Results are shown in Fig. 5.

Students report that their professors cared about them (and their learning) more when they also reported interactive teaching. Of particular note, nearly $100 \%$ of the students reporting interactive teaching also reported they felt their instructors cared about them and their learning. This relationship appeared for all demographic groups across gender, race, and major status. 


\section{Professor Caring \& College Course}

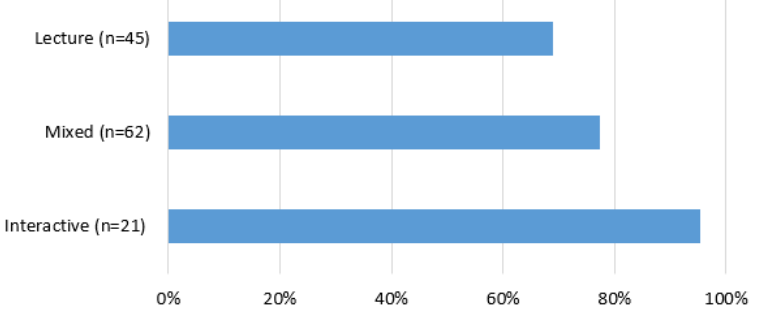

FIG 5. Percent of students reporting faculty cared about them by type of instruction they reported in their STEM major.

The finding that feeling cared about is correlated with teaching style suggests that part of the success of interactive teaching styles may simply lie in the way it fosters connection between student and faculty. When students reported feeling their professors did not care they often attributed it to a distant teaching style. Reasons given for feeling cared about frequently focused on feeling a personal connection with the professor. For example: “... with my immunology class and my neurobiology class they definitely took time to get to know us" - White Female Major.

\section{DISCUSSION}

Our findings have two limitations. First, our data is correlational. While a deeper read of the comments students made indicates some causal mechanisms at work, inferences about causation are limited. Second, due to self-selected sample, tests for possible statistical significance in differences by demographic group are inappropriate. With these cautions in mind, we observed several trends that have important implications.

Discussions and efforts around representation in STEM, frequently center on the deficit model [3], where individuals in underrepresented groups are the focus. The deficit model assumes underrepresentation is the effect of something some groups are missing (i.e. exposure) and that representation can be achieved primarily through providing something (i.e workshops) to make up for the deficit. In this model, the larger environment and its role is largely overlooked. Efforts are put into changing those from underrepresented groups rather than questioning and changing the environment they are in. While efforts to fill in gaps in individuals are likely necessary to address underrepresentation, findings such as ours indicate they are likely not sufficient.

We found patterns that indicate that teaching style is likely to have differing impacts on students of varied demographics. We see indications that greater use of interactive teaching (associated with higher learning gains for all demographic groups) may positively impact the retention of both white women and women of color. We found that women who left a STEM major reported the greatest disconnect between the style they preferred and the style they encountered in their courses.

Further, we found that interactive teaching is associated with greater feelings that the instructor cares and that women of color generally feel the least care. These two findings suggest that increasing the use of interactive teaching may increase the level of perceived care felt by women of color and therefore increase retention. (Feelings of personal connection with faculty are associated with persistence in college [4].)

Taken together, our findings indicate that a likely avenue to improve representation in STEM is to change the environment students encounter as they pursue STEM by improving teaching for all students. Through increased use of interactive teaching methods, robustly demonstrated to improve outcomes for all demographics, the environment is likely more supportive of groups which have traditionally not pursued or dropped out of STEM.

\section{ACKNOWLEDGMENTS}

We are grateful to the NSF for funding this project. NSF-STEP, DUE-0969286

\section{REFERENCES}

1. A. Madson, S. McKagan, and E. Sayre, Phys. Rev. ST Physics. Educ. Res. 9, 020121 (2013).

2. R. J. Beichner, J. M. Saul, D. S. Abbott, J. J. Morse, D. L. Deardorff, R. J. Allain, S. W. Bonham, M. H. Dancy, and J. S. Risley, Research-Based Reform of University Physics, edited by E. F. Redish and P. J. Cooney (2007). Reviews in PER Vol. 1

3. Irizarry, Jason. "Cultural deficit model." Education. com (2009).

4. Tinto, V. Leaving college: Rethinking the causes and cures of student attrition. University of Chicago Press, 5801 S. Ellis Avenue, Chicago, IL 60637. (1987) 